\title{
Impact of Urban Infrastructure Development on Power Loss of Solar Photovoltaic Modules
}

\author{
Shah Naveed ${ }^{1}$, Saddam $\mathrm{Ali}^{2}$, Dr.Saim Saher $^{3}$ \\ ${ }^{1}$ Research Scholar, ${ }^{2}$ Research Associate, ${ }^{3}$ Assistant Professor US-Pakistan Centre for Advanced Studies in Energy, \\ University of Engineering and Technology Peshawar, Pakistan, \\ snaveed1@asu.edu1, saddam.ali@uetpeshawar.edu.pk ${ }^{2}$, s.saher@uetpeshawar.edu.pk ${ }^{3}$ \\ Received: 20 May, Revised: 24 May, Accepted: 02 June
}

\begin{abstract}
Solar photovoltaics pose as a major technology in shifting reliance from non-renewable to renewable energy resources. Soiling is a key issue which is further escalated by dust blowing as a result of road infrastructure development in urban environments. The Peshawar Bus Rapid Transit Corridor (BRT) project provided a chance to carry out this study aimed at corelating scale of infrastructure development with heightened PV losses and formulating ways to cope with the problem. A site offering an urban topography located at a distance of $1.2 \mathrm{~km}$ away from the BRT route was identified. The soiling station at this site was operated for one month and the data was processed to identify the prevailing soiling loss trends. The soiling station recorded losses in excess of $20 \%$ within the first 2 weeks of operation. It was found that clouds and strong winds had no significant role in retarding the losses. However, frequent rainwater cleaning at one instant reversed the losses back to $0 \%$. It was thus established that cleaning the modules with water on a two week basis during large scale road development works in and around urban areas could keep the losses within a bearable limit.
\end{abstract}

Keywords - Solar Photovoltaics, Soiling losses in PV, Road infrastructure development, Peshawar Bus Rapid Transit Corridor, Soiling loss mitigation.

\section{INTRODUCTION}

Public infrastructure development is a significant contributor to economic growth whereas acquiring selfsufficiency and sustainability in energy resources is the key to maintaining the growth $[1,2]$. The industrial revolution resulted in a sustained and substantial increase of GDP per capita in real terms. However, the unprecedented deployment of fossil fuels it accompanied resulted in dwindling of conventional energy resources and a massive infusion of harmful emissions resulting in global warming and health problems [3]. It is reported that Pakistan on average loses 4$6 \%$ of its GDP annually due to insufficiency of adequate infrastructure [4]. Currently, Pakistan ranks $9^{\text {th }}$ in the Belt and Road Infrastructure Development Index and the goal of this research is to contribute towards attaining sustainable growth through minimizing PV losses due to soiling resulting from such fast-paced infrastructure development [5]. The quest for urban infrastructure development has an inherent issue of increasing pollution that results in impacting the performance of solar PV power production adversely. To maintain a sustainable growth, it is needed to minimize these effects by devising effective coping procedures.

Pakistan's energy demand is rapidly increasing because of urbanization and industrialization. Pakistan's primary energy supply in the financial year 2017 was 92.9 MTOE [6]. It consisted of $47.5 \%$ of natural gas, $30.5 \%$ of oil, and $10.9 \%$ of hydel, $9.2 \%$ of coal, $1.2 \%$ nuclear and $0.7 \%$ LPG [6]. In the coming fifteen years the demand will increase to 122 MTOE, thus increasing the annual energy import bill to more than US $\$ 41$ billion compared to the total annual energy import bill of US $\$ 7.5$ billion in 2008 [7]. To meet this galloping energy demand is a significant challenge for Pakistan and increasing reliance on renewable energy resources is a feasible solution. Reducing any setbacks faced by solar PV due to soiling losses is therefore a key goal.

The $21^{\text {st }}$ century saw initiation of a remarkable research effort into renewable and green energy technologies as a means of mitigating the impending consequences. Studies suggest that renewables could contribute 20 to $50 \%$ of energy supplies in the second half of the century. Solar PV is one of the most widely applied technologies for power generation. The average power available at the earth's surface in the form of solar radiation is more than 1500 times the entire global power demand [8]. Solar technologies can be classified into solar thermal and solar electric or PV systems. PV systems make use of photo-electric effect to harvest energy from a photon to drive DC electric charges around the circuit. Presently almost $87 \%$ of the PV cells are fabricated using Silicon [9]. The power output and efficiency of PV systems are key to determining cost per watt. Greater the output lesser will be the cost. Among the factors impacting the yield of PV modules, the irradiance fluctuation is the most pertinent to the overall power output [10]. PV modules have a capacity factor of 15 to $25 \%$ depending on the location of installation. The downtime can be further exacerbated by the losses in irradiance due to shading caused in most powerplants by soil accumulation on the modules as dust particles sit on them [11]. 
Transportation development projects in urban settings are to reduce congestion, excessive fuel consumption resulting from traffic jams, and travel time as well as to increase connectivity, safety, environmental conservation, and economic activity. New road development projects may have many advantages in terms of boosting social and economic growth by increasing mobility and enhancing services availability. However, letting the unintended consequences go unnoticed would be a serious misrepresentation of facts. The immense rapid urbanization and pressure on urban transport sometime result in conception of road infrastructure development projects in urban centres without prior due diligence to all the factor that could generate a negative result. Our focus here is on investigating the performance degradation of PV modules in the immediate vicinity of these project sites because of the increased soiling losses resulting from accumulation of dust particles on PV panels after emanating from these sites.

The soiling problem in context of PV module performance studies arises from shading due to factors such as dust accumulation, snow, and bird droppings on the module surface. The most common and dominating among these factors is dust accumulation. Dust is a generic term for particulate matter with a diameter of less than $500 \mu \mathrm{m}$ or 0.5 $\mathrm{nm}$ [12]. The degree of dust accumulation depends on factors such as climatic, location-based meteorological, environmental, and nearby ongoing construction scale conditions. The importance of soiling losses investigation and mitigation is derived from the understanding that around $75 \%$ of world population resides in countries that constitute the EPIA's designated 66-country sunbelt as shown in figure 1 [13]. Majority of these regions are widely prone to the existence of desert areas and have significant pollution indices. Moreover, the geographically dictated need to configure the PV modules at flat tilt angles in these areas results in robust soiling impact on PV module performance [14].

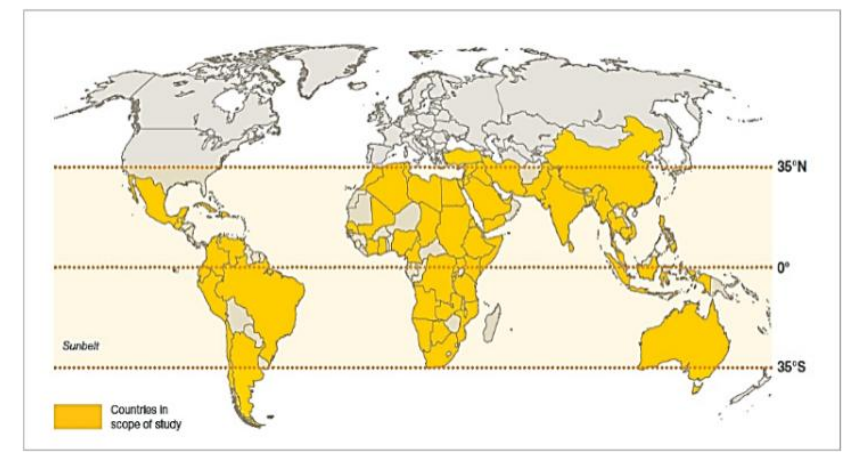

Figure 1. Focus countries of the Sunbelt; EPIA [13]

This study focused on the impact of increased dust accumulation resulting from the construction phase of the Peshawar Bus Rapid Transit Project (BRT) on PV performance. The BRT project is aimed at providing the local population with a sustainable urban transport system. The 26 $\mathrm{km}$ long integrated bus transit corridor system once operational will directly benefit 0.5 million people in terms of shorter travel times, lower vehicle operating costs, better air quality, and environmental conservation through reduced carbon emissions. A complete restructuring of the corridor with the provision of BRT dedicated lanes, 31 stations, 2 depots, mixed traffic lanes, sidewalks, and a proper drainage system are some of the major components that required immense excavation, construction, and remodeling works [15]. Such large-scale infrastructure development works always come with the infusion of huge concentrations of dust particles into the air for an extended period of time. The BRT route has been divided into three reaches and Reach 3 which stretches from Aman Chowk to Hayatabad is particularly affected by astonishing levels of dust blowing in the area. The existing PV installations in the vicinity of the route are affected adversely by unimaginable levels of soiling. This state of affairs prompted the study to probe into the soiling losses caused by such large-scale infrastructure development in the area.

\section{METHODOLOGY}

\section{A. Site identification:}

A portion of area along the BRT Reach 3 was identified that could provide the opportunity to investigate the impact of increased soiling on PV performance of the modules installed in a nearby urban area as shown in figure 2 . The results from the soiling station output voltage data were then utilized to find out what mitigation approaches can be employed to curb the soiling losses in the face of similar scale urban infrastructure development activities.

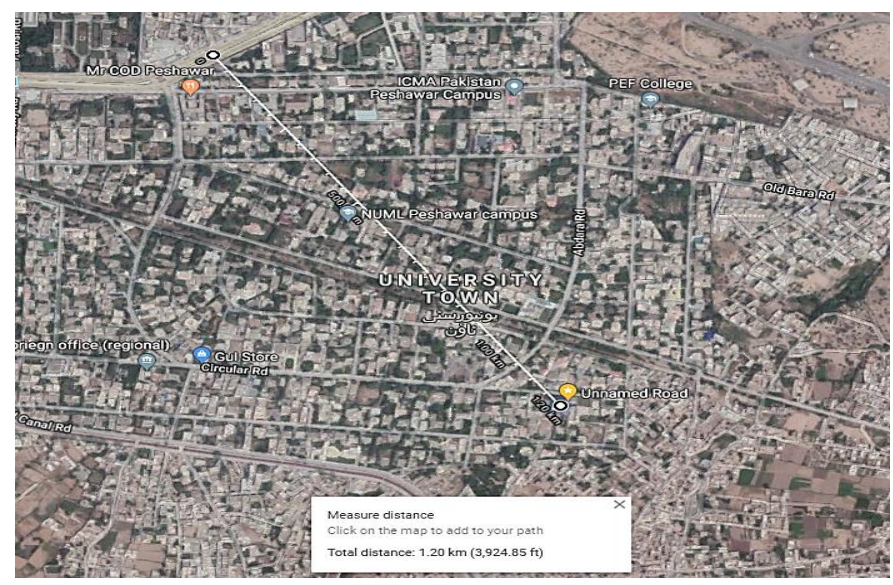

Figure 2. Soiling station installation site in urban area $1.2 \mathrm{~km}$ away from the BRT route

One of the two identical half cells of the soiling station at the site was cleaned manually at 12 pm every day and the other was left uncleaned for the whole month. The module voltage readings were compiled for the month of August 2018 and employed in subsequent analyses. The soiling loss factor (SLF) was calculated for the site at noon every day and the entire data resulted in a total of $31 \mathrm{SLF}$ values for the course 
of the study. The SLF values along with rain gauge readings helped in understanding the observed trends.

\section{B. Data Collection and Analysis}

The soiling station was operated for the time span of the study. Transparent hatch was employed for the cleaned modules and was opened manually at $12 \mathrm{pm}$ every day to take readings. The time for taking readings was 2-3 minutes during which the hatch stayed open and the maximum window for human error was kept at 5 minutes with a \pm 2.5 minute uncertainty. The reason for not automating the hatch-opening process was to avoid any unwanted deviations and discrepancies in the form of system break down and the technical assistance mandatory otherwise and cost incurred in the event of a fault was also a reason for carrying out the operation manually.

\section{Data Collection Period}

The data collection period was decided to be from August 1, 2018 to August 31, 2018. This period of time provided the opportunity to investigate soiling losses with the onset of vigorous construction activities undertaken around that month. This month also provided the opportunity to investigate any effect of rainwater cleaning during the monsoon season observed throughout the first 2 weeks of the month. Data was compiled daily from 6 am to $7 \mathrm{pm}$ and the most important data points were those at noon.

\section{Data Plots}

The data thus obtained was plotted subsequently. Five data plotting intervals were employed for the site in such a manner that the first interval spanned the first three days of the month and the remaining four intervals spanned seven days each in an orderly manner. These plots helped tremendously in understanding the effects of meteorological phenomena such as clouds, rain, and storm on the voltage output of the PV half cells used. The peak values at noon for both the cleaned and soiled panels were used to calculate the soiling loss factor for the entire period on daily basis.

\section{E. Soiling Loss Factor Calculation}

The outdoor soiling data from the soiling station obtained between August 1, 2018 and August 31, 2018 was processed to calculate the daily Soiling Loss Factor. The output voltage from both the soiled and the clean half cells was used in the calculation and the August 1 data was utilized in SLF normalization. The normalized SLF values were then used to calculate daily percentage soiling losses at the site. Finally, the SLF values were compared along with rain data against time to reveal any important trends and findings.

\section{RESULTS AND DISCUSSION}

The output voltage versus time graphs for both the soiled and clean half cells were plotted as shown in figures 3-7, and the peak voltage values of the individual plots were utilized to determine the soiling loss factor (SLF) values for each day. The first peak value obtained for the soiled panel was around $0.0843 \mathrm{~V}$ and that for the clean module was $0.0921 \mathrm{~V}$ on August 1. These values were used to calculate SLF for day 1 which was later used for normalization of data from the station and calculating normalized SLF values for the subsequent days throughout the study.

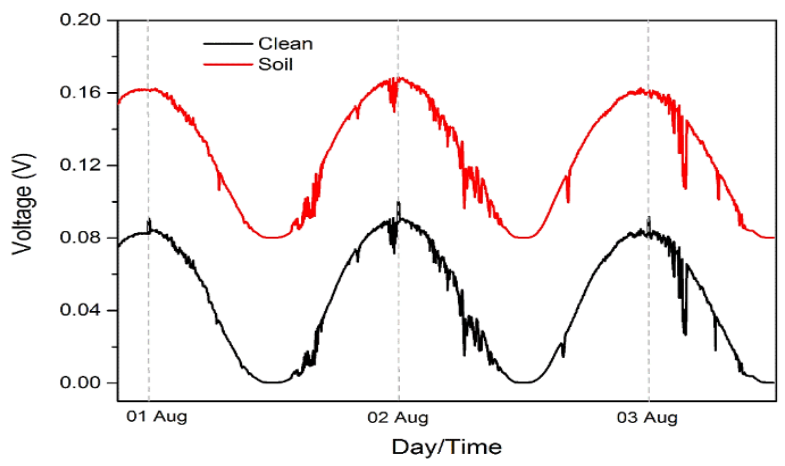

Figure 3. Output of clean and soiled panels during 1-3 August 2018

The offset of $0.08 \mathrm{~V}$ was added to the soiled panel data to plot the soiled panel voltage values over the clean panel voltage values in the same graph. On the noon of August 2, the peak value for the soiled module was $0.0782 \mathrm{~V}$ and that for the cleaned module was $0.09 \mathrm{~V}$ which resulted in the normalized SLF to drop to 0.95 from 1. This trend continued throughout the study with the SLF values dropping with time as evident from the data recorded for the first week as given in table 1 and was challenged only in the event of adequate rain.

TABLE I. SLF VALUES AND PERCENTAGE SOILING LOSSES DURING THE FIRST WEEK

\begin{tabular}{|l|c|c|c|c|c|c|c|}
\hline Date & $\begin{array}{c}\text { 1- } \\
\text { Aug }\end{array}$ & $\begin{array}{c}\mathbf{2 -} \\
\text { Aug }\end{array}$ & $\begin{array}{c}\mathbf{3 -} \\
\text { Aug }\end{array}$ & $\begin{array}{c}\text { 4- } \\
\text { Aug }\end{array}$ & $\begin{array}{c}\mathbf{5 -} \\
\text { Aug }\end{array}$ & $\begin{array}{c}\text { 6- } \\
\text { Aug }\end{array}$ & $\begin{array}{c}\text { 7- } \\
\text { Aug }\end{array}$ \\
\hline $\begin{array}{l}\text { S (Soiled } \\
\text { Module) }\end{array}$ & 0.08 & 0.08 & 0.07 & 0.07 & 0.07 & 0.07 & 0.07 \\
\hline $\begin{array}{l}\text { C (Clean } \\
\text { Module) }\end{array}$ & 0.09 & 0.09 & 0.09 & 0.09 & 0.09 & 0.09 & 0.09 \\
\hline S/C & 0.92 & 0.87 & 0.82 & 0.84 & 0.80 & 0.78 & 0.77 \\
\hline $\begin{array}{l}\text { Sf/Cf (First } \\
\text { day) }\end{array}$ & 0.92 & 0.92 & 0.92 & 0.92 & 0.92 & 0.92 & 0.92 \\
\hline $\begin{array}{l}\text { SLF } \\
\text { (Normalized) }\end{array}$ & $\mathbf{1}$ & $\mathbf{0 . 9 5}$ & $\mathbf{0 . 9}$ & $\mathbf{0 . 9 2}$ & $\mathbf{0 . 8 7}$ & $\mathbf{0 . 8 5}$ & $\mathbf{0 . 8 4}$ \\
\hline $\begin{array}{l}\text { \% Soiling } \\
\text { losses }\end{array}$ & 0 & 5 & 10 & 8 & 13 & 15 & 16 \\
\hline
\end{tabular}




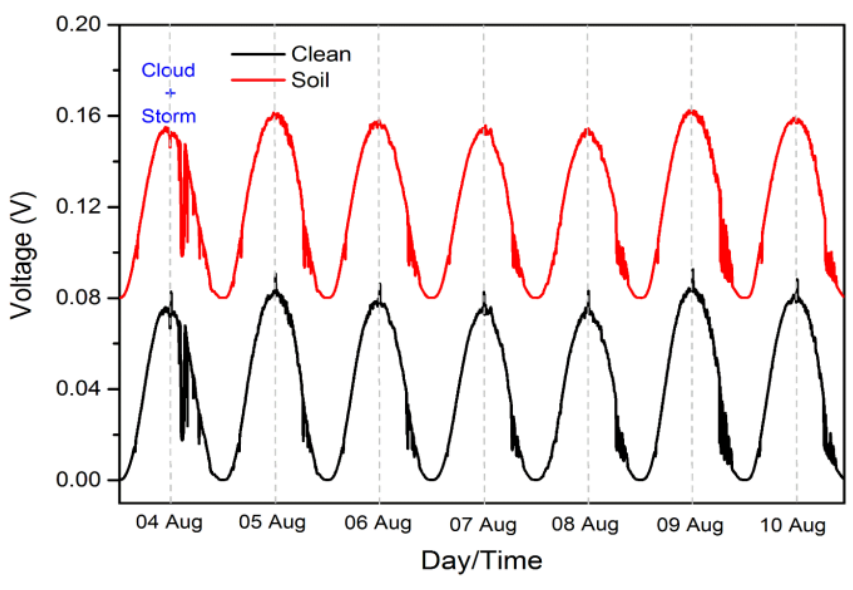

Figure 4. Output of clean and soiled panels during 4-10 August 2018

On August 4 the region witnessed clouds and storm as specified in figure 4 . The soiled panel performed slightly better than it had the previous day. The reason behind this minor recovery is the storm which may have taken away the loosely adherent dust particles from the panel surface. Nevertheless, the previous trend continued and the SLF values kept decreasing during the subsequent days. This showed that the events of clouds and storm did not have any significant effect on the relative performance of the soiled and the clean solar PV panels. In other words, clouds and storm did not affect soiling losses to a significant extent. The small betterment in the soiled panel performance can only be due to the action of the winds alone since clouds alone do not bring about any such change. In the presence of clouds, both the soiled and the clean panels received the same number of photons. The reduced irradiance levels under cloud cover do not affect the SLF values since it in itself is a ratio of the clean and soiled panels outputs operating under the same conditions of irradiance.

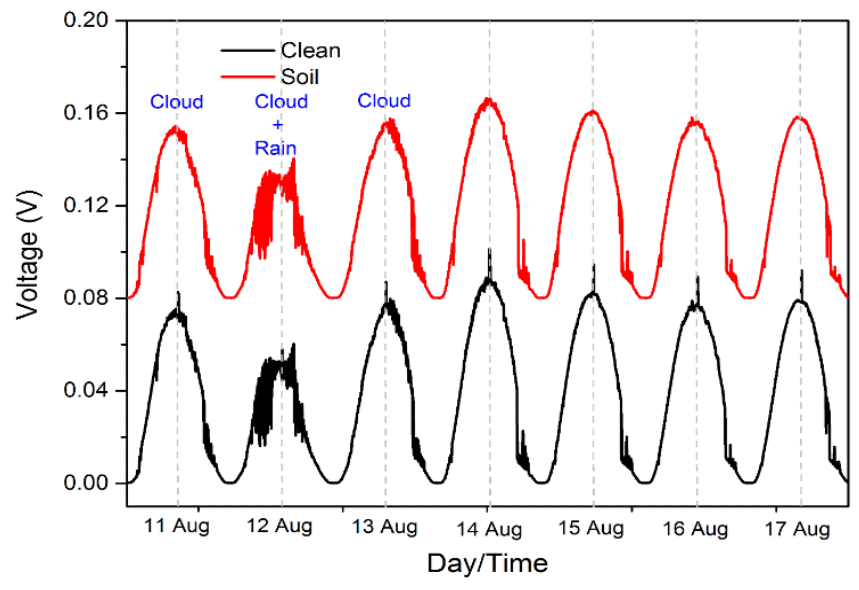

Figure 5. Output of clean and soiled panels during 11-17 August 2018

There were again clouds on August 11 but the peak values for both the panels did not deviate from the previous trend. However, the event of rain on August 12 resulted in a notable effect on the soiled PV panel performance as evident from the depressions in both the respective curves for that day in figure 5. The rainwater cleaning of the soiled PV panel resulted in enhanced performance and regaining the SLF value near to 1.

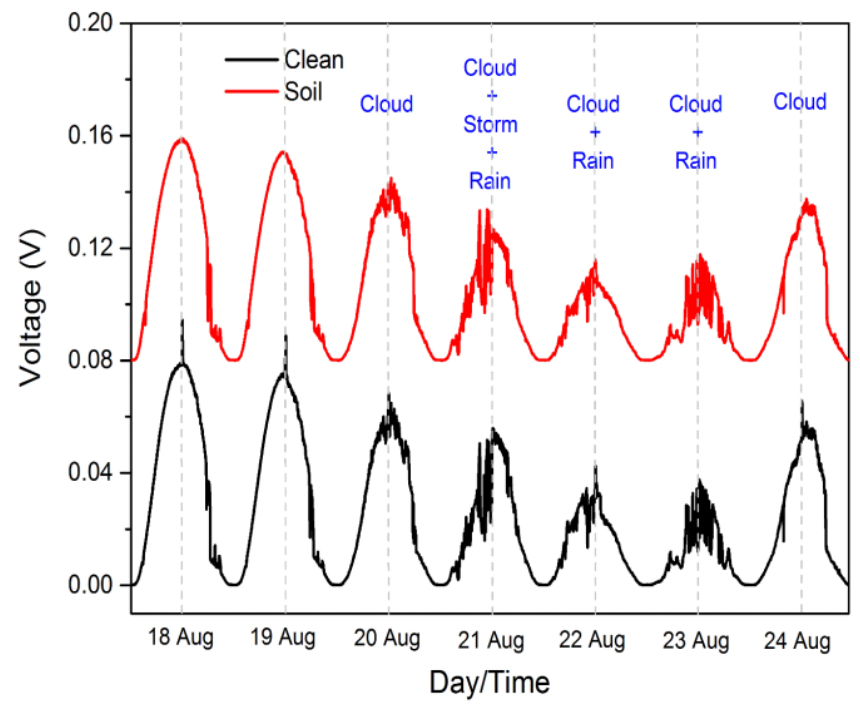

Figure 6. Output of clean and soiled panels during 18-24 August 2018

In the following 8 days until 21 August there was no rain and the declining SLF trend was back in action as evident from figure 6 . The output of the soiled module kept decreasing and the gap in the peak values of the clean and soiled modules kept on increasing. This resulted in gradual increase in percentage soiling losses. Even the presence of clouds on 20 August did not impact this declining trend in the SLF values as described earlier.

The last day of the third week observed clouds and rain accompanied by strong winds. This time the rain gauge measurement showed $3 \mathrm{~mm}$ of rain on 21 August and the following two days having $4 \mathrm{~mm}$ rainfall each. The persistent cloud cover present at noon from 21-23 August resulted in reduced PV performance for both the soiled and cleaned panels. However, the relative difference in the performance of the cleaned and the soiled modules was reduced remarkably. The soiled panel surface was relieved of the accumulated dust by repeated rainfall until it was completely free of the particulate matter building up for the previous three weeks of the study. This in turn resulted in increasing of the SLF value. This time the base line of no soiling loss was achieved on August 24 and both the soiled and the clean panels recorded the same ratio of peak values of output voltage as observed on day 1 . The percentage soiling losses were thus back to $0 \%$. 


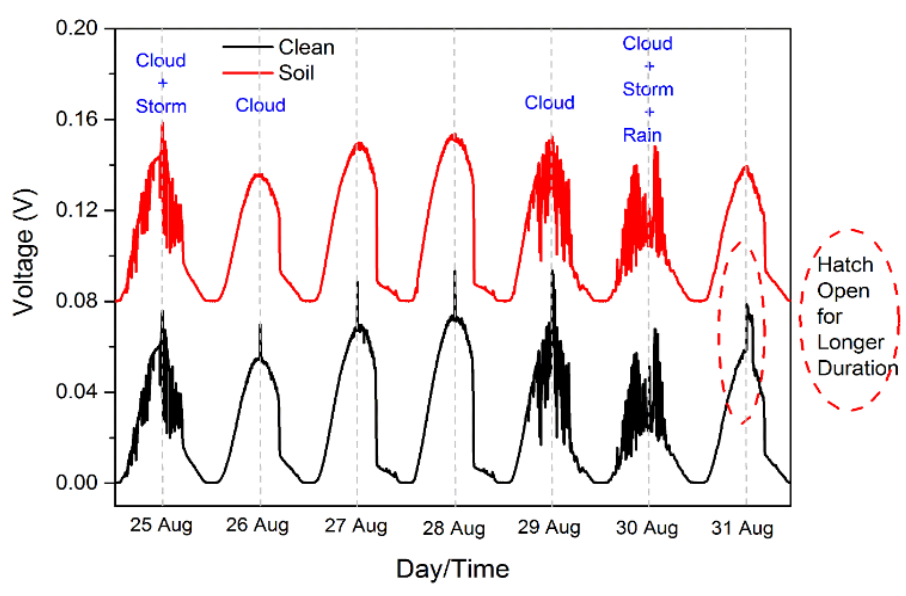

Figure 7. Output of clean and soiled panels during 25-31 August 2018

There were clouds on 24 August and both clouds and strong winds on 25 August, but the event of rain did not take place as specified in figures 6 and 7. The SLF values started declining with the passage of time and soiling losses became apparent on 28 and 29 August. The next day it rained for 3 $\mathrm{mm}$ and it was enough to easily reverse the SFL declining trend. This made it obvious that the rain frequency had a huge impact towards reducing the soiling losses by natural cleaning of the soiled panel. Also, the clean module hatch remained open beyond the stated error window of 5 minutes on the final day of the study for some unavoidable reasons and the resulting plot shape strayed to some extent as can be seen in figure 7 .

TABLE II. THE EFFECT OF RAIN ON SLF VALUES AND PERCENTAGE SOILING LOSSES

\begin{tabular}{|c|c|c|c|}
\hline Date & $\begin{array}{c}\text { Rain } \\
(\mathbf{m m})\end{array}$ & SLF & $\begin{array}{l}\text { \% } \\
\text { Soiling } \\
\text { loss }\end{array}$ \\
\hline 11-Aug-18 & & 0.8 & 20 \\
\hline 12-Aug-18 & 3 & 0.97 & 3 \\
\hline 13-Aug-18 & & 0.96 & 4 \\
\hline \multicolumn{5}{|l}{} \\
\hline 20-Aug-18 & 2 & 0.82 & 18 \\
\hline 21-Aug-18 & 2 & 0.98 & 4 \\
\hline 22-Aug-18 & 4 & 1 & 0 \\
\hline 23-Aug-18 & 4 & 0.97 & 3 \\
\hline 24-Aug-18 & \multicolumn{3}{|l}{} \\
\hline \multicolumn{2}{|l|}{} & 0.85 & 15 \\
\hline 29-Aug-18 & & 0.96 & 4 \\
\hline 30-Aug-18 & 3 & 0.94 & 6 \\
\hline 31-Aug-18 & &
\end{tabular}

By looking at the values in table 2, recorded for the day before, during, and the day after an event of rain, it becomes obvious that rainwater cleaning of the modules contributed significantly towards decreasing soiling losses to some extent. It is notable that soiling losses dropped from $20 \%$ to just $3 \%$ on
12 August as a result of only $3 \mathrm{~mm}$ of rainwater cleaning effect. Moreover, three consecutive events of rain on 21, 22, and 23 August took the SLF back up to 1 which means all the soiling losses were virtually reversed to $0 \%$. Finally the $3 \mathrm{~mm}$ rain on August 30 had an impact in the same fashion which resulted in soiling losses to get reduced from $15 \%$ to $4 \%$. The percentage SLF values and the corresponding percentage soiling losses at noon every day for the entire study period are represented in figure 8.

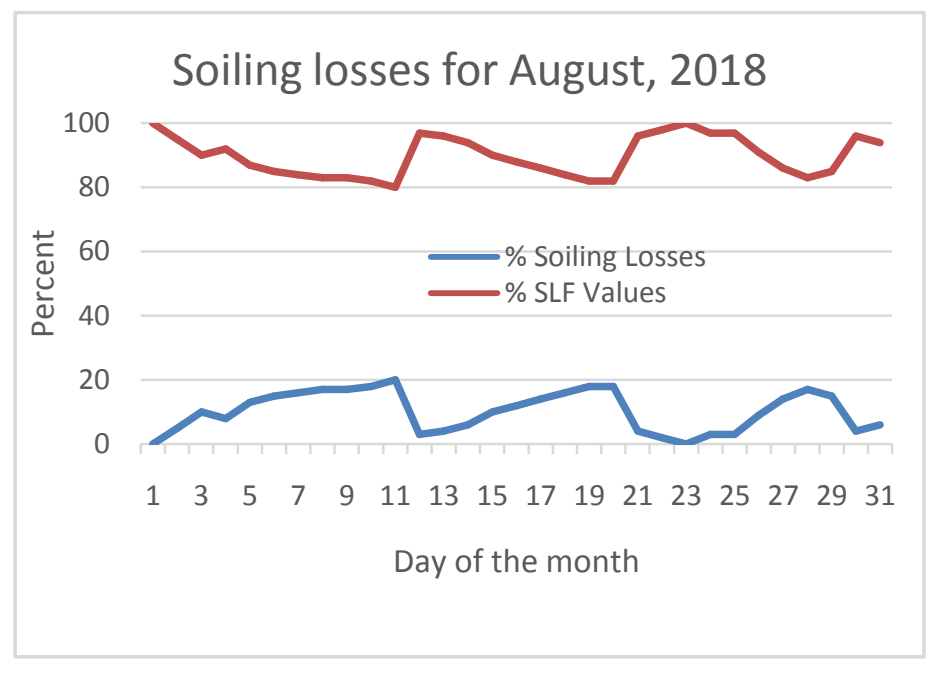

Figure 8. Percentage SLF values and the corresponding percentage soiling losses for the entire study period

\section{CONCUSLION}

The findings of the study showed that the site under consideration would have likely faced more than $20 \%$ soiling losses after the $12^{\text {th }}$ day of installation, if there had been no rain. It is thus easy to assume that any urban PV installations experiencing road infrastructure development activity comparable in scale to the Peshawar BRT might easily experience soiling losses in excess of $20 \%$ towards the end of every two weeks operation cycle beginning with the cleaning of the panel surface. It therefore becomes necessary to clean the modules at least every fortnightly. The data showed that urban areas with low altitude PV installations reveal a continuous increase in soiling losses over time thus in case of no rain the cleaning of solar PV with water has to be scheduled at least every 2 weeks.

In conclusion, the soiling data approaching the $20 \%$ maximum soiling loss baseline for the present study within the first 2 weeks of installation is a stark indicator that such largescale urban infrastructure development activities have a negative impact on solar PV performance. Hence, procedures such as dust control and other environmental protection safeguards must be followed in conjunction with optimal site selection for future PV plants installations in urban areas. 


\section{ACKNOWLEDGEMENT}

The author is thankful for the funding provided for this study by the United States Agency for International Development (USAID) through the USPCAS-E, UET Peshawar. Gratitude also goes to Dr. Saim Saher for his help and guidance throughout this study.

\section{REFERENCES}

[1] Tanveer A, Manan N., "Impact of Infrastructure on Economic Growth of Pakistan.” Journal of Economic Research,Edition 1, 2016.

[2] B. Srinivasu, P. Srinivasa Rao, "Infrastructure Development and Economic growth: Prospects and Perspective". Journal of Business Management \& Social Sciences Research, Vol. 2, No. 1, 2013.

[3] P. Vries, Encyclopaedia of the Modern World, Vol. 4. Oxford University Press, 2008, pp. 158-161.

[4] State Bank of Pakistan, "The Pakistan Infrastructure Report", State Bank of Pakistan Infrastructure Task Force, 2018.

[5] The News International, "Pakistan ranked 9th in infrastructure development index", 2017.

[6] Chaudhry, M.A., Raza, R. and Hayat, S.A., 2009. Renewable energy technologies in Pakistan: prospects and challenges. Renewable and Sustainable Energy Reviews, 13(6-7), pp.1657-1662.

[7] International Energy Agency (IEA), Global Energy \& CO2 Status Report (2017).

[8] J. Goldemberg et al., "World energy assessment: Energy and the Challenge of Sustainability". New York, NY: United Nations Development Programme, 2000, p. 239.

[9] Module 7, Renewable energy technologies, Sustainable energy regulation and policymaking for Africa - TRAINING MANUAL, 2018.
[10] S. Canada, "Quality Assurance: Impacts of Soiling on Utility Scale PV System Performance”. SolarPro Magazine no. 6.3, pp. 14-20, 2013

[11] K. Menoufi, "Dust accumulation on the surface of Photovoltaic Panels: Introducing the Photovoltaic Soiling Index (PVSI)", MDPI Sustainability Journal, 2017.

[12] T. Sarver, A. Al-Qaraghuli and L. Kazmerski, "A comprehensive review of the impact of dust on the use of solar energy: History, investigations, results, literature, and mitigation approaches", Renewable and Sustainable Energy Reviews, vol. 22, pp. 698-733, 2013.

[13] European Photovoltaic Industry Association, "Unlocking the Sunbelt Potential of Photovoltaics", 2010.

[14] T. Weber, N. Ferreti, F. Schenider, A. Janker, M. Trawney and J. Berghold, "Impact and Consequences of soiling and cleaning of PV modules", NREL Photovoltaic Reliability Workshop (PVMRW), Denver, 2015.

[15] Peshawar Development Authority, "LARP Implementation Monthly Progress Report May 2018", Government of Khyber Pakhtunkhwa, 2018

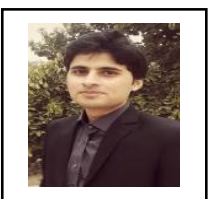

Shah Naveed: The author was born in Pakistan in the year 1992. He holds a bachelors degree in Mechanical Engineering from University of Engineering and Technology Peshawar. He also has completed a certificate course in Technology Entrereneurship from Arizona State University. The author cherishes his experience working at the Engineering Research Centre and the Macro Technology Works at the ASU, USA. Currently, he is pursuing masters degree in Materials for Energy Storage and Conversion at the US-Pakistan Centre for Advanced Studies in Energy, UET Peshawar, Pakistan. 